\title{
Research on Mathematical Model of Shaanxi Vocational Education Reform and Development
}

\author{
Cheng Hongping, Shao Zhiwei \\ Xi'an Eurasia University, Xi 'an, Shaanxi, 710065, China
}

Keywords: Shaanxi, Vocational education, Analytic hierarchy process, Model

\begin{abstract}
Based on the reform and development of vocational education in China, combined with the current situation of shaanxi province, through the analytic hierarchy process model to comb out the influencing factors and through the sorting, give reasonable Suggestions.
\end{abstract}

\section{Introduction}

In 2014, the first year of China's comprehensive and comprehensive reform of vocational education, the CPC Central Committee and the State Council made a series of major arrangements to accelerate the development of vocational education. They successively issued the State Council's Decision on Accelerating the Development of Modern Vocational Education, the Opinions on Developing Pilot Work of Modern Apprenticeship and other strategic documents on the development of national vocational education involving top-level design. The Party Central Committee, the State Council and leaders at all levels have always attached great importance to vocational education. Since the reform and opening up, Shaanxi's vocational education has made great progress, but at present, vocational education is still a relatively weak link in Shaanxi's national education system. As a result of college enrollment expansion, secondary vocational schools are gradually facing the threat of survival, and the survival of some higher vocational colleges is also facing similar difficulties.

\section{Analytic Hierarchy Process Model Analysis of Shaanxi Vocational Education Reform and Development}

Through on-the-spot visits and questionnaires, the research was conducted in schools such as Shaanxi polytechnic institute, Shaanxi Energy Vocational and Technical College, Xi 'an Technician College and Xi 'an Commercial and Tourism Technician College to listen to the reports of relevant teachers in the investigated schools and to think about the development of vocational education. The analysis shows that the current factors affecting Shaanxi vocational education include the changing trend of school scale, the contribution of trained talents to the local economy, the space for higher vocational and secondary vocational graduates to improve their academic qualifications, the situation of enterprises participating in the training of school talents, the difficulties in attracting enterprises to participate in the training of school talents, how the teaching staff supports the training of applied talents, and whether the training and development of teachers are consistent with the direction of school running, etc.

\subsection{The Structural Diagram of the Analytic Hierarchy Process Model for the Reform and Development of Shaanxi Vocational Education is established}

According to the current situation of the reform and development of Shaanxi vocational education, we use AHP model to rank the personnel training, development scale, cooperation between industry and university, and teaching staff as the main influencing factors.

First of all, establish the hierarchical analysis structure as shown in the following figure: 


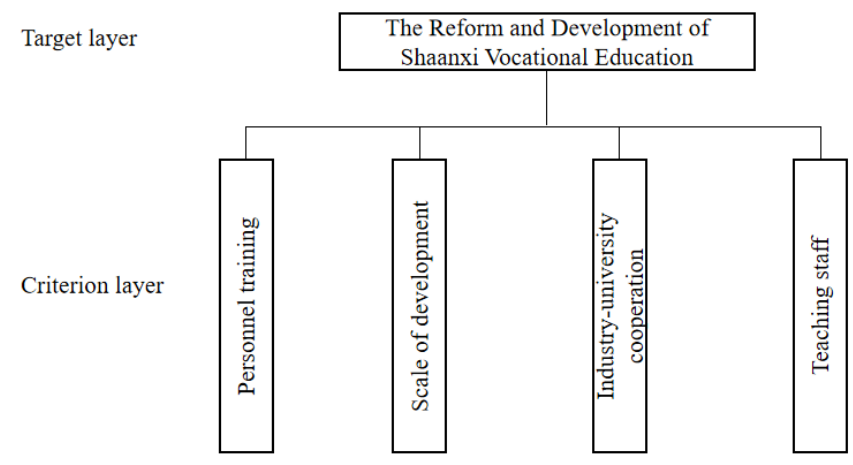

\subsection{Construct the Judgment Matrix}

The hierarchical structure reflects the relationship between factors, but the proportion of each criterion in the criterion layer in the target measurement is not necessarily the same, that is to say, in the minds of decision makers, they each occupy a certain proportion.

When determining the proportion of factors affecting a certain factor in the factor, the main difficulty encountered is that these proportions are often difficult to quantify. In addition, when there are many factors that affect a certain factor, when directly considering the degree of influence of each factor on the factor, the decision-maker will often put forward data inconsistent with the degree of importance he actually thinks, or even a group of data with hidden contradictions due to incomplete consideration and consideration of one thing and one thing and loss of another. In order to see this clearly, the following assumption can be made: smashing a stone weighing $1 \mathrm{~kg}$ into $n$ small pieces, you can accurately weigh them and set them as $w_{1}, \cdots, w_{n}$ now, please estimate the proportion of the weight of the $n$ small pieces to the total weight (he cannot know the weight of each small piece). this person is not only difficult to give an accurate ratio, but may also provide contradictory data because he cares for one thing and loses another.

Definition 1 if matrix $A=\left(a_{i j}\right)_{n \times n}$ satisfies

$$
\text { (i) } a_{i j}>0,\left(\text { ii) } a_{j i}=\frac{1}{a_{i j}}(i, j=1,2, \cdots, n)\right.
$$

It is called a positive reciprocal matrix(Easy to see $a_{i i}=1, i=1, \cdots, n$ ).

As to how to determine the value of $a_{i j}$, Saaty et al. suggested to quote the numbers 1-9 and their reciprocal as scales. The following table lists the meaning of scale 1-9:

\begin{tabular}{|l|l|}
\hline Scale & Meaning \\
\hline 1 & Indicates that the two factors are of equal importance compared to each other. \\
3 & The former is slightly more important than the latter. \\
5 & It means that the former is obviously more important than the latter. \\
7 & It means that compared with the two factors, the former is more important than the latter. \\
$2,4,6,8$ & $\begin{array}{l}\text { Compared with the two factors, the former is more important than the latter. } \\
\text { Reciprocal }\end{array}$ \\
Indicates the intermediate value of the above adjacent judgment \\
$i$ is $a_{j i}=\frac{1}{a_{i j}}$.
\end{tabular}

From a psychological point of view, too many grades will exceed people's judgment ability, which not only increases the difficulty of judgment, but also easily provides false data. Saaty et al. also compared the correctness of people's judgment results under various scales with experimental methods. the experimental results also show that 1-9 scale is the most suitable.

For the main factors mentioned in this article that affect the reform and development of Shaanxi vocational education: personnel training, development scale, cooperation between industry and university, and teaching staff, according to the impact on vocational education, combined with the scale of 1-9, we get the following matrix 


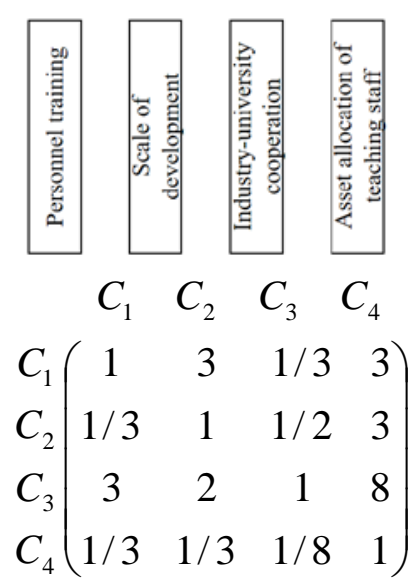

\subsection{Consistency check and hierarchical single sorting}

The judgment matrix $A$ corresponds to the feature vector $W$ of the maximum feature value $\lambda_{\max }$, and after normalization, it is the ranking weight of the relative importance of the corresponding factors of the same level to a factor of the previous level. This process is called hierarchical single ranking.

The steps for consistency check of the judgment matrix are as follows:

(1)Calculating consistency index $C I$

$$
C I=\frac{\lambda_{\max }-n}{n-1}=\frac{4.20-4}{3}=0.066
$$

(2)Find the corresponding average random consistency index. For $n=1, \cdots, 9$, Saaty, the value of $R I$ is given as shown in the following table:

\begin{tabular}{|l|lllllllllll}
\hline$n$ & 1 & 2 & 3 & 4 & 5 & 6 & 7 & 8 & 9 \\
\hline$R I$ & 0 & 0 & 0.58 & 0.90 & 1.12 & 1.24 & 1.32 & 1.41 & 1.45 \\
\hline
\end{tabular}

The value of $R I$ is obtained by randomly constructing 500 sample matrices: randomly extracting numbers from 1-9 and their reciprocal to construct a positive reciprocal matrix, obtaining the average $\lambda_{\max }^{\prime}$ of the largest characteristic root, and defining

$$
R I=\frac{\lambda^{\prime}{ }_{\max }-n}{n-1}
$$

(3)Calculate the consistency ratio $C R$

$$
C R=\frac{C I}{R I}
$$

When $C R<0.10$, it is considered that the consistency of the judgment matrix is acceptable, otherwise, the judgment matrix should be modified appropriately.

The $C I=0.066$ calculated above and the $R I=0.9$ generation found in the table can be obtained

$$
C R=\frac{C I}{R I}=\frac{0.066}{0.9}=0.073<0.10
$$

Therefore, the consistency test is passed, and the matrix is solved by MATLAB software. The results are as follows:

$$
\omega=\left(\begin{array}{llll}
0.24 & 0.16 & 0.53 & 0.07
\end{array}\right)
$$

That is to say, the order of the above influencing factors is: cooperation between industry and university, personnel training, development scale, and teaching staff. 


\section{An Effective Way to Reform and Develop Shaanxi Vocational Education}

According to the ranking of factors in the criteria layer that affect Shaanxi vocational education by the analytic hierarchy process model, the factors of cooperation between industry and university are the most important, followed by the factors of talent cultivation, development scale and finally the factors of teachers. Therefore, we can give strategic suggestions to Shaanxi vocational education in this order.

\subsection{As Soon as Possible, Establish Relevant Systems to Promote Industrial and Academic Cooperation}

Shaanxi Province should improve various systems of school-enterprise cooperation as soon as possible and formulate laws and regulations to promote school-enterprise cooperation. Establish and improve the school-enterprise cooperation planning, cooperation governance and cooperation training mechanism, so as to integrate talent training into the enterprise production service process and value creation process. Vocational colleges and cooperative enterprises should continuously improve the systems of knowledge sharing, curriculum development and updating, order cultivation, on-the-job practice, production and practical training, exchange and appointment, staff training, collaborative innovation, etc. And continue to increase the number of enterprises to hand over projects to schools to be completed by teachers and students in the teaching and learning process; It is also possible for enterprise management personnel to undertake the teaching tasks of the school. In terms of practical teaching, the school is urged to build a practical training base in the enterprise and the enterprise to build a talent training and training base in the school. Explore the cooperation forms of school-enterprise integration, such as introducing schools into factories, factories into schools, front stores and back schools, to promote the development of vocational education more steadily.

\subsection{All Colleges and Universities Have Worked out a Good Plan for Personnel Training}

Vocational colleges of all colleges and universities clearly define the orientation of running schools and highlight their characteristics. On the basis of the existing achievements, vocational colleges have further defined the orientation of running schools, highlighted their own characteristics and sought development. First of all, do a good job in market research and grasp the future development direction. No matter whether it is a secondary vocational school or a higher vocational school, it should take the human resources market in the region as the breakthrough point and do a good job in market research. Secondly, make clear the goal and orientation of running a school: combining with the data of market research, further analyze the selected talent demand points, further study the competency model of these positions, and form a school-running orientation with its own characteristics through research and demonstration with enterprise experts and experts in the field of vocational education. Finally, give full play to their own advantages and highlight their own characteristics. To formulate the school's medium-and long-term strategic development plan, to do a good job of process management in its implementation, and to make timely adjustments according to the environment, to ensure accurate positioning and distinctive features.

\subsection{The Scale of Development is to improve the Quality of the School Rather than to expand the Scale}

Compared with other provinces with larger scale of vocational education, the scale of vocational education in our province is not small, and there is no problem of shrinkage and shortage.

"Chinese Business Education” shows that Shaanxi Province has the highest cramming rate in the country. From 2010 to 2012, 80,000, 74,000 and 70,000 examinees gave up their college entrance examinations and chose to resume their studies. The serious shrinkage in the scale of secondary vocational education and the large number of candidates who give up specialized admission show that vocational education is not attractive to candidates. Most candidates are unwilling to choose vocational education and prefer to go to undergraduate courses. 
Therefore, the focus of the development of vocational education in our province is to improve the quality rather than to expand the scale, and to open up the overpass between higher vocational education and ordinary higher education to increase the attractiveness of candidates.

\subsection{Strengthen the Construction of Teaching Staff}

The construction of teaching staff is the core to ensure the realization of talent training objectives and continuously improve teaching quality. In strengthening the construction of teaching staff in our school, especially the construction of double-qualified teachers, all vocational colleges can continuously increase the introduction of high-quality and highly educated talents. Strengthening teacher training; To train professional leaders and key teachers as the focus of teacher construction; The teacher training mechanism should be improved. We will start with various forms of teacher competitions and strive to turn our school's teaching staff into a trinity of excellent theoretical teaching, practical training guidance and production practice.

\section{Acknowledgements}

Project of Shaanxi Provincial Education Department [17JK1034].

\section{References}

[1] Chen Lin. Shaanxi Province secondary vocational schools will be reduced from 567 to 300 within 2 years [EB/OL]. http://news.hsw.cn/system/2014/1226/199201.shtml.

[2] Zhang Jing, Bi Huazhang. Energy downturn, weak solid investment, Shaanxi's economic growth "to protect 10" pressure surge [EB/OL]. http://www.sei.gov.cn/ShowArticle2008.asp? ArticleID=254014.

[3] Cao Ying. (2015). Construction of Student Education Management System in Higher Vocational Colleges from the Perspective of Active Education [J]. Journal of Beijing Institute of Technology, vol. 14, no. 2, pp. 63-64.

[4] Shaanxi Provincial Department of Education. The State Council's Education Supervision Team specially supervises Shaanxi Province's vocational education [EB/OL]. http://www.snedu.gov.cn/jynews/jyyw/201506/16/49748.html.

[5] Zhao Juming. Reform Quality Responsibility: Modernization of Higher Education-Proceedings of the 2013 International Forum on Higher Education [C]. Ningbo, Zhejiang, China: China Higher Education Association, 2013.

[6] Cao Yingguo. (2015). Construction of Student Education Management System in Higher Vocational Colleges from the Perspective of Positive Education [J]. Journal of Beijing Institute of Technology, vol. 14, no. 2, pp. 63-64 